Ekonomia - Wroclaw Economic Review 26/2 (2020)

Acta Universitatis Wratislaviensis

No 3992

https://doi.org/10.19195/2658-1310.26.2.6

Igor Wysocki

ORCID: 0000-0002-4926-4010

Independent Scholar

igorwysocki82@wp.pl

Dawid Megger

ORCID: 0000-0002-2827-4607

Nicolaus Copernicus University in Toruń

dawid.megger95@gmail.com

\title{
Rejoinder to Wiśniewski on the Austrian welfare economics
}

Date of submission: 7.01.2020; date of acceptance: 25.05 .2020

JEL classification: B41, B53, D60, D63, P14

Keywords: welfare economics, Austrian economics, Rothbard, property rights, voluntary exchange, theory of threat

\section{Abstract \\ Rejoinder to Wiśniewski on the Austrian welfare economics}

In the present short paper, we attempt to response the incisive criticisms directed at us by the eminent scholar Jakub Bożydar Wiśniewski. His rejoinder is nothing short of excellent, being concise and yet packed up with many insightful remarks, which gave us a sufficient reason to write this rejoinder in our turn. Our polemical note is structured as follows: we take Wiśniewski's successive (as they appeared in his original rejoinder) critical points and reply them, while trying to treat our adversary's position as charitably and seriously as possible and attempting to sharpen our standpoint even further.

First, Wiśniewski recounts the Rothbardian position on welfare. It looks as though we might as well skip this part. However, it would be ill-advised because some of these points already have a bearing on whether ours or his conclusions are correct. Says Wiśniewski (2019, 25-26): “According to Rothbard, since embracing the subjectivist theory of value makes interpersonal comparisons of utility impossible, only voluntary interactions between purposive agents can be justifiably regarded as increasing social utility." Wiśniewski goes on to say that "only 
voluntary interactions between purposive agents can be justifiably regarded as increasing social utility." It might be inferred that Wiśniewski subscribes to the premise that we endorse in the forthcoming part of our paper; that is, that whatever is efficient is voluntary. Yet, it seems that he believes instead that whatever is voluntary is efficient. This is evidenced by the fact that he sees a fundamental difference in their respective efficiency between the two scenarios in our thought experiment (tax collector as compared to a potential competitor), while claiming that in the first case the payment is involuntary and therefore inefficient, whereas in the other it is voluntary and therefore effiicient. ${ }^{1}$ Indeed, if Wiśniewski subscribed to the premise that whatever is efficient is voluntary (as we do), there would be no disagreement between us and our very polemics would be rendered void. For our very point is that some voluntary exchanges (see: our example with blackmail, accounted for by the Nozickian theory of unproductive exchange and bolstered by our putatively rather convincing thought experiment) (Wysocki, Megger, 2019) are indeed inefficient, the point which Wiśniewski strongly dissociates himself from. Incidentally, to anticipate our forthcoming remarks a little, we claim that whether voluntary interactions imply Pareto-superior moves is exactly the point at issue. We, as indicated above, happen to claim that the entailment goes, if anything, in the opposite direction; that is, whatever is efficient is voluntary.

Wiśniewski $(2019,26)$ unabashedly continues: "Thus, the free market, understood as the embodiment of large-scale social cooperation based exclusively on the principles of contract and consent, emerges as the only environment capable of impacting social welfare in an unambiguously positive manner." But then again, this conclusion is valid only if we accept the axiom (whatever is voluntary is efficient) and in our view, this very axiom is, just to reiterate, the very point at issue.

Then, Wiśniewski proceeds to scrutinize the validity of our thought experiment (blackmailer vs tax collector case). He says to this effect: "Most importantly, the threat issued by the tax collector disrupts the free market system - that is, the sum total of voluntary interpersonal interactions aimed at mutual welfare maximization" (Wiśniewski, 2019, 26). This, according to Wiśniewski, enables him to view our two cases as "significantly dissimilar." And surprisingly enough, we simply concur with our critic. Indeed, we posit that the two cases are dissimilar exactly in voluntariness-coercion dimension and only in this aspect. We endeavoured to design our thought experiment as to allow voluntariness to vary (that is, we allowed for the lack thereof) while purportedly keeping everything else equal. It cannot count as any indictment against us that our two scenarios are "significantly dissimilar" in this respect because it is exactly what our thought experiment strived to achieve. If Wiśniewski insists that voluntariness/involuntariness makes the world of a difference for the respective efficiency in the two transactions, he simply begs the

${ }^{1}$ In other words, the difference between our position and Wiśniewski's is that we believe voluntariness to be merely a necessary condition of Pareto-efficiency, whereas Wiśniewski believes it to be a sufficient one. 
question against us since the necessary relevance of voluntariness to efficiency is precisely what we question.

The following fragment by Wiśniewski $(2019,26)$ lets our position remain unscathed for exactly the same reason: "Thus, paying the tax collector off does not preserve the pre-existing status quo, but rather, first, deprives the payer of the money that he originally possessed, thus leaving him worse off and, second, testifies to the fact that he now inhabits an interventionist, zero-sum world instead of the voluntarist, positive-sum world that he inhabited before the tax collector showed up." But there are additional problems here. In the case of a potential competitor, we are also "deprived ${ }^{2}$ of the money that [we] originally possessed"; and hence, Wiśniewski fails to establish a difference. And what follows: aren't we then equally rendered "worse off" in the case of a tax collector just as in the case of a potential competitor? To prove that, Wiśniewski would have to appeal to some other criterion than being simply "deprived of the money one originally possessed" because in this respect the two scenarios do not vary at all. ${ }^{3}$ Maybe the fact that "he now inhabits an interventionist, zero-sum world instead of the voluntarist, positive-sum world that he inhabited before the tax collector showed up" would allow to significantly distinguish our two cases then? But this basically still assumes (and therefore begs the question!) that it is voluntariness that is an essential feature of Pareto-superior moves. Our position is rather that whatever is efficient is voluntary, which is of course equivalent to saying that whatever is involuntary is inefficient. In this respect we definitely side with Wiśniewski; however, our axiom (whatever is efficient is voluntary) predicts market inefficiencies ${ }^{4}$, whereas Wiśniewski (and Rohtbard) rules out this possibility almost by definition. ${ }^{5}$ In the last statement of this section, Wiśniewski $(2019,26)$ adds: "Paying off the potential business competitor, on the other hand, is a purely contractual interaction, which, instead of preserving the status quo, establishes a more favorable business environment as far as the payer is concerned." Yet, this criticism was anticipated

2 "Deprived" being used secundum quid here. The pros hen sense of "deprivation" would normally imply the initiation of aggression. We are grateful to Łukasz Dominiak for pressing us on this point. However, since this (mis)use of ours is fully dependent upon the distinction between voluntariness and involuntariness (once we are deprived of money, the transaction was involuntary; once we are not, the transaction was voluntary), this linguistic point connected with "deprivation" does not carry any additional normative force against us over and above the problem of whether voluntariness/involuntariness has a bearing on efficiency, the problem we deal with throughout our rejoinder.

3 Certainly, the caveat mentioned in the footnote above applies here.

${ }^{4}$ Or market failures, to use a bad term. On a more serious note, our position predicts that some outcomes on the free market are just as bad as governmental interventions; e.g. any blackmail scenarios.

5 There is no way we can (even contingently) have market failures as long as we claim that whatever is voluntary is efficient. In other words, market failures is a conceptual impossibility once we make rights-based voluntariness an essential property of Pareto-superior moves. 
in our original paper, in which we said that it might be claimed that by buying a tax collector off, his victim buys a "more favourable social environment."

Once Wiśniewski $(2019,26)$ delves into the blackmail case, he starts playing fast and loose with ceteris paribus, the point we also anticipated in our original paper. This is testified by the following fragment: "Even if, upon refusing his offer, the »blackmailee« were to find out that the »blackmailer« is actually a fully competent businessman, that would not necessarily decrease the former's welfare, since in the market system competitors can learn from each other's successes, obtaining information crucial to the development of their respective entrepreneurial visions." But resorting to such rhetoric moves is not fair. After all, the nature of thought experiments is such that it assumes many irrelevant differences away. It is only via keeping everything else equal that we test what kind of difference the element that we allow to vary can make (in our case, it is voluntariness/coerciveness of a proposal that varies). We might as well argue that the victim of a tax collector's welfare does not diminish either merely because the latter's victim learns how to avoid paying taxes - a very useful skill indeed. He would have never learned that skill but for the existence of a tax collector. The point of all this is that we believe that all contingencies should be gotten rid of, with this postulate stemming from the very nature of thought experiments as such. Wiśniewski $(2019,26-27)$ concludes this paragraph by saying: "In sum, to characterize the two cases under consideration as identical in terms of their outcomes is a logically inadmissible proposition, which ignores the essential praxeological differences between responding to a business offer and acting under the threat of violence." This simply restates Wiśniewski's position and does not provide any argument against our claim that sometimes voluntary interactions (blackmail) are as inefficient as governmental interventions.

The next paragraph of Wiśniewski's rejoinder $(2019,27)$ commences with Wiśniewski accusing us of "playing with normalcy" and using inappropriate baselines: "preserving one's liberty in an extortionist system and maintaining one's market niche in a competitive business environment are most definitely not identical benchmarks as far as praxeologically understood Pareto-efficiency is concerned." Yet, we cannot make our way through "praxeologically understood Pareto-efficiency." Is it a subspecies of some generic understanding of Pareto-efficiency? And do we, willy-nilly, thereby employ some non-praxeological understanding of Pareto-efficiency? If so, we would appreciate if Wiśniewski provided us with some much needed clarification. However, we might venture some interpretation of the notion he employs. If what is praxeologically understood Pareto-efficiency simply amounts to right-based idea of normalcy, then the Rothbardian defense of free-market follows - since $\mathrm{x}$ is a voluntary choice only if no rights are violated (or threatened to be violated) (Wertheimer, 1989, 202-221). ${ }^{6}$

${ }^{6}$ However, doesn't it make the invocation of the concept of efficiency, as construed by Rothbard, argumentatively redundant? Couldn't Rothbard simply defend free market on the grounds of natural rights alone? After all, he does so in his other works, such as Ethics of Liberty or For a New 
But if our construal is correct, then Rothbard most clearly begs the question. Whether free market is efficient is to be established and not basically assumed in the concept of efficiency. To reiterate, since free market is defined as a totality of voluntary transactions, it is enough to define Pareto-efficiency in terms of voluntariness (resp. in terms of respecting property rights) and the conclusion that free markets are efficient must inevitably follow. Yet, it only shifts the problem: we cast doubt upon the premise that whatever is voluntary is efficient. This remains to be proved and not assumed.

The concluding sections of Wiśniewski's rejoinder focus on our allegation that the Rothbardian argument is viciously circular. Wiśniewski claims here that "rather than arbitrarily defining Pareto-superiority as the result of voluntary interactions, Rothbard derives such a definition from the action axiom and its subjectivist implications, including the impossibility of making interpersonal utility comparisons. Consequently, his definition of the free market as the sum total of voluntary transactions is likewise not arbitrary, but deductively justified, grounded in the nature of catallactic development and in the fundamental distinction between the economic and the political means." We would be very grateful if Wiśniewski clearly explained how the said derivation proceeds here. Still, the above point is perhaps the most interesting bone of contention between us. In a sense, all deductive arguments beg the question for there is nothing in the conclusion that was not first in the premises. Yet, this is not our point here. Rather, we are willing to conclude that Rothbard's argument is viciously circular as propositional identity between a premise and conclusion is exemplified therein. In other words, the premise that whatever is voluntary is efficient is actually propositionally identical to the conclusion that free markets are efficient. What the second premise (free market is a totality of voluntary transactions) achieves is to substitute free markets for voluntary transactions. That is, the second premise is a mere definitional linguistic point. To illustrate it, let us cite Sinnott-Armstrong's argument with Ohio-Buckeye State (Sinnott-Armstrong, 1999, 176): "Suppose Kate says to Larry, 'Mary lives in Buckeye State'. Larry responds, 'No. I've never heard of the Buckeye State, but Mary lives in Ohio'. Kate then argues,

Ohio is the Buckeye State.

Mary lives in Ohio.

Mary lives in the Buckeye State.

Liberty: The Libertarian Manifesto. The point is that since a sufficient condition for a transaction to constitute a Pareto-superior move is person A's non-right-violating behaviour (and hence, person B's acting voluntarily), then what does efficiency add to what right talk has already achieved? What is worse, once one defines efficiency in terms of rights, we can investigate efficiency only within a theory of rights. And funnily enough, it is actually your rights when exercised that make my action efficient. And to add insult to injury, the rights-based definition of voluntariness is very problematic in itself (see: Olsaretti, 1998), which definitely merits a separate paper. 
The second premise is equivalent to the conclusion, since Ohio is the Buckeye State. So Kate's argument is weakly circular. But Kate's use of the argument is still informative for Larry, who did not know that Ohio is the Buckeye State." By analogy, we conclude that the Rothbardian argument does not beg the question given a Larry-like audience. Specifically, the argument does not beg the question only when it is addressed at the audience which does not know the meaning of free market. Only such an audience would enjoy a Eureka moment of finding out (upon learning that free market is identified with a totality of voluntary transactions) that free market is efficient. The skeptical audience already equipped with a definition of free market will inevitably remain skeptical after having been presented with the Rothbardian argument. After all, in this case, somebody who doubts the conclusion (free market is efficient) would equally doubt the major premise (whatever is voluntary is efficient). And this observation tallies well with Sinnott-Armstrong's (1999, 10) conditions for an argument to beg the question: "To avoid begging the question, one's reason to believe the premise might have to be independent of either (a) one's belief in the conclusion or (b) one's reason to believe the conclusion." If two entities are identical, then whatever is true of the former must be true of the latter and vice versa. This must also apply to propositions. If two propositions are identical, then whatever property the former has, must be the property of the latter and vice versa. So trivially, if there is a specific reason for which one believes the conclusion, it must be for the same reason that one believes the major premise. In other words, anybody who doubts that free market is efficient cannot be convinced by the Rothbardian argument and neither are we.

To summarize, maybe some of Wiśniewski's remarks seemed to be sound, but as we indicated above they miss the point after all. He still does not provide us with a deductive inference which shows the way that right-based voluntariness is grounded in praxeology and its axioms. It seems that the proposed necessary relationship between efficiency and voluntariness (or more precisely that all voluntary actions are efficient) is on a par with the conclusion that free market is efficient; so, it would take Wiśniewski to argue (to make an independent argument) for this very premise rather than to assume it to ultimately convince us. Even if our article might have some defects, it seems to us that Wiśniewski unfortunately did not come up with any argument that was not considered by us before. So, ultimately, we still remain convinced that Austrian welfare economics, grounded upon a libertarian theory of natural rights, is not satisfying.

\section{References}

Olsaretti, S. (1998). Freedom, force and choice: against the rights-based definition of voluntariness. Journal of Political Philosophy, 6 (1), 53-78.

Rothbard, M.N. (1998). The Ethics of Liberty. New York-London: New York University Press.

Rothbard, M.N. (2006). For a New Liberty. A Libertarian Manifesto. Auburn, AL: Ludwig von Mises Institute.

Ekonomia - Wroclaw Economic Review 26/, 2020

(C) for this edition by CNS 
Rothbard, M.N. (2008) [1956]. Toward a reconstruction of utility and welfare economics. In M. Sennholz (ed.), On Freedom and Free Enterprise: Essays in Honor of Ludwig von Mises (224-262). Auburn, AL: Ludwig von Mises Institute.

Sinnott-Armstrong, W. (1999). Begging the question. Australasian Journal of Philosophy, 77 (2), 174-191.

Wertheimer, A. (1989). Coercion. Princeton: Princeton University Press.

Wiśniewski, J.B. (2019). Austrian welfare economics: A reply to Wysocki and Megger. Ekonomia Wroclaw Economic Review, 25(3), 25-28.

Wysocki, I., Megger, D. (2019). Austrian welfare economics: A critical approach. Ekonomia - Wroclaw Economic Review, 25(1), 73-80. 